University of Tennessee Health Science Center

UTHSC Digital Commons

Fall 11-20-2020

\title{
An Analysis of Patient-Generated Health Data in Assisting Nurses and Physicians to Better Treat Patients with Hypertension
}

Diana Chaparadza

University of Tennessee Health Science Center

Follow this and additional works at: https://dc.uthsc.edu/hiimappliedresearch

Part of the Health and Medical Administration Commons, and the Health Information Technology Commons

\section{Recommended Citation}

Chaparadza, Diana, "An Analysis of Patient-Generated Health Data in Assisting Nurses and Physicians to Better Treat Patients with Hypertension" (2020). Applied Research Projects. 73. . https://doi.org/ 10.21007/chp.hiim.0080

https://dc.uthsc.edu/hiimappliedresearch/73

This Research Project is brought to you for free and open access by the Department of Health Informatics and Information Management at UTHSC Digital Commons. It has been accepted for inclusion in Applied Research Projects by an authorized administrator of UTHSC Digital Commons. For more information, please contact jwelch30@uthsc.edu. 
Running head: HOW PGHD IS ASSISTING NURSES AND PHYSICIANS TO TREAT HYPERTENSION

An Analysis of Patient Generated Health Data in Assisting Nurses and Physicians to Better Treat Patients with Hypertension.

\author{
Diana Sevenzayi \\ University of Tennessee Health Science Center \\ Masters of Health Informatics and Information Management \\ Advisor: Dr. Sajeesh Kumar \\ IRB\# 20-07355-XM
}

Fall 2020 
AN ANALYSIS OF PGHD IN ASSISTING NURSES AND PHYSICIANS TO BETTER TREAT

PATIENTS WITH HYPERTENSION

\begin{abstract}
Patient Generated Health Data (PGHD is not new but it has gained more attention these past years due to the advent of smart devices, remote monitoring devices and many applications on various smart devices. PGHD reflects medications and treatment, lifestyle choices, and health history. Unlike traditional medical visits, where clinicians collect and manage data within their offices, PGHD is collected by patients throughout the course of their day and provides an insight of how they are responding to treatments or lifestyle choices. Examples include blood glucose monitoring or blood pressure readings using home health equipment, exercise and diet tracking using mobile applications or wearable devices such as the Fitbit or other smart watches.
\end{abstract}


AN ANALYSIS OF PGHD IN ASSISTING NURSES AND PHYSICIANS TO BETTER TREAT

PATIENTS WITH HYPERTENSION

\section{Table of Contents}

Chapter 1: Introduction...........................................................5

Background of Problem.........................................5

Purpose of Study ..........................................6

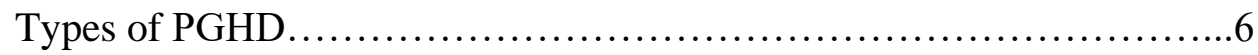

Opportunities and Weaknesses of using PGHD........................

Limitations of Study........................................8

Chapter 2: Review of Literature..................................................10

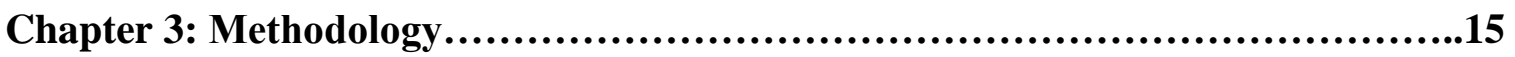

Research Design............................................15

Population and Sample Design..................................15

Data Collection Procedures.......................................15

Data Analysis................................................18

Response Rate............................................... 18

Chapter 4: Results..................................................................19

Chapter 5: Conclusions and Recommendations..................................26

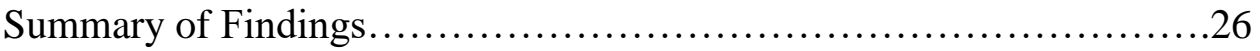

Conclusions.....................................................26

Recommendations............................................27

References................................................................................28

\section{List of Figures}

Figure 1: Flow Chart of the Results from PGHD Literature search...................13

Figure 2: Survey Cover Letter............................................ 16

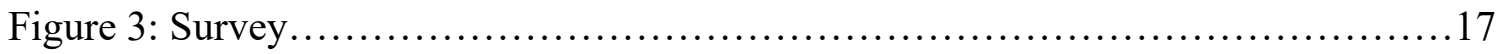


AN ANALYSIS OF PGHD IN ASSISTING NURSES AND PHYSICIANS TO BETTER TREAT

PATIENTS WITH HYPERTENSION

\section{Appendix A}

Consent Form .......................................................... 30

\section{Appendix B}

Survey Questionnaire................................................. 31 
AN ANALYSIS OF PGHD IN ASSISTING NURSES AND PHYSICIANS TO BETTER TREAT

PATIENTS WITH HYPERTENSION

\section{Chapter 1 - Introduction}

\section{Background}

The Office of the National Coordinator for Health IT defines PGHD as any health-related data including health history, symptoms, biometric data, treatment history lifestyle choices, and other information created, recorded, gathered, or inferred by or from patients and their designees to help address a health concern. The patients are responsible for capturing the data and share it with their healthcare providers. PGHD can be gathered using digital health tools such as mobile apps, online questionnaires, wearables, and connected medical devices can be used to assist patients become more engaged in their care. This approach has the potential to inform better clinical decision making with patients engaged in the decision-making process (Shapiro et al., 2012). The Centers for Disease Control (CDC) reports that about 1 in 3 U.S. adults or about 75 million people have high blood pressure. Only about half (54\%) of these people have their high blood pressure under control by taking medications or regular exercises.

In addition, Mozaffarian, D. et al. (2015) states that hypertension is a major risk factor for cardiovascular disease (CVD), with an estimated annual cost of US $\$ 46$ billion in the United States. In addition, 29\% of American adults have been diagnosed with hypertension and among those only 52\% controlled blood pressure under the recommended level of 140/90 mm Hg Nwankwo, T. et al. (2011-2012). Furthermore, $28 \%$ of Americans have prehypertension, a precursor of hypertension characterized by BP of 120/80 mm Hg to 139/89 mm Hg (Ostchega, Y., 2006). Using PGHD can allow 
AN ANALYSIS OF PGHD IN ASSISTING NURSES AND PHYSICIANS TO BETTER TREAT

PATIENTS WITH HYPERTENSION

patients to monitor their blood pressure and get advice from clinicians to set individual targets on ways to improve their health such as diet and exercises.

\section{Purpose of Study}

The objective of this study is to analyze how PGHD is assisting nurses and physicians to better treat patients with hypertension. The literature shows that patient health improves when they use PGHD as it encourages them to exercise better lifestyles such as exercising and eating healthy. Clinicians are able to set target goals depending on each patient. Most people are now using mobile devices or wearables to capture their fitness data. Are young people with hypertension utilizing PGHD or is it the older population that is more focused on improving their health with PGHD? The findings could be used to determine if PGHD can be utilized to optimize medication treatments and patient care.

\section{Types of PGHD}

The following are PGHD types according to Shapiro et al. (2012):

- Patient measured vital signs using a device and recorded by patient e.g. temperature, blood pressure, blood glucose, and weight. These data might be captured manually, by reading a mechanical or electronic device, or automatically captured via a monitoring device.

- Self-reported lifestyle data, this can be recorded by patient of family member e.g. caloric intake, diet, exercise, hydration, medication adherence, ability to perform activities of daily living. The patient or a patient designee would typically manually capture these data. 
AN ANALYSIS OF PGHD IN ASSISTING NURSES AND PHYSICIANS TO BETTER TREAT

PATIENTS WITH HYPERTENSION

- Self-reported as perceived quality of life data e.g. mood, sleep quality, level of pain, social contacts. The patient or a patient designee would typically manually capture these data.

- Data, other than health-related that enable the patient to be known to the provider on a personalized individual basis.

\section{Opportunities and Weaknesses of using PGHD}

With the increasing number of people using smart phones and mobile applications PGHD helps patients manage to better manage their health while providers get an opportunity to offer more meaningful services. When patients send data to physician offices it also enables quick intervention to emergencies before illnesses become more serious. With remote monitoring, clinicians are able to prioritize their tasks depending on each patient data outcomes in order to better service them. Subsequently, patients with the highest risks can quickly receive attention and given steps to improve their health before moving on to patients who are self-managing their blood pressure. In addition, PGHD can assist researchers in identifying ways to improve consumer and provider education and find better ways of improving PGHD.

However, there are also challenges pertaining the use of PGHD. Complications for utilizing PGHD include patient inability to interpret results, lack of interoperability between health care systems to transmit PGHD data points, and potential for data breach. Challenges such as these may discourage patients from embracing technology that better improves their health. In addition, privacy and security issues continue to be a huge issue 
AN ANALYSIS OF PGHD IN ASSISTING NURSES AND PHYSICIANS TO BETTER TREAT PATIENTS WITH HYPERTENSION

because patients worry that the data may accidentally end up in third party hands. Lastly, not many physicians have integrated PGHD into their electronic health records because

policy makers have not created right incentives for providers to include PGHD. Providers are concerned about financial impacts of PGHD because it takes a lot of time and resources to review and manage PGHD. The integration of PGHD and EHRs would make it easier for data transmission thus significantly improving administrative efficiency. As a result, patient satisfaction also increases.

The lack of standards for both PGHD and interoperability of devices is a growing concern in our healthcare system. The Office of the National Coordinator and industry standards organizations such as HL7 continue to actively working on developing a middleware model to facilitate better interoperability between EHRs and PGHD. The future of PGHD ultimately depends on advances in technologies that will make it possible for the transformation of these data into more meaningful information that improves clinical outcomes.

\section{Limitations of Study}

Within the development of this research limitations were identified. During the literature review process, there were a limited number of relevant articles connected to the research subject thus creating a research gap to compare with. The project was also limited in that it was conducted in a small hypertension clinic. In addition, due to COVID-19, healthcare facilities switched to telehealth and most nurses were no longer dealing with the nurses but physicians only. Consequently, the number of nurses 
AN ANALYSIS OF PGHD IN ASSISTING NURSES AND PHYSICIANS TO BETTER TREAT PATIENTS WITH HYPERTENSION

available to take the survey was decreased. With the COVID-19, it was not safe to go to the facility to distribute the survey. 
AN ANALYSIS OF PGHD IN ASSISTING NURSES AND PHYSICIANS TO BETTER TREAT

PATIENTS WITH HYPERTENSION

\section{CHAPTER 2 - Review of Literature}

A literature search was performed by researching articles about Patient-Generated Health Data. Articles used were found from the following databases: PubMed, Journals of Medical Internet Research and the American Journal of Medicine. Electronic databases were used to identify relevant journals. The most successful keyword searches were hypertension or blood pressure, PGHD, and healthcare digital tools. In all, 15 abstracts were read and found to be possibly relevant to the topic. Of those 15 , only 10 were available in full text. After review, 2 articles were found to have some relevance PGHD and how it is assisting physicians and nurses while treating hypertension. The first article found to correlate the most with the research topic deals with patients with hypertension who enrolled in a home-based digital-medicine blood pressure program. The second article explored the management and diagnosis of hypertensive patients or suspected hypertensive patients using wirelessly transmitting home-based self-monitoring of blood pressure data (SMBP).

Milani et al. (2016) explored the perspectives of patient engagement using digital tools and primary care providers in utilizing home-based self-monitoring of blood pressure data into electronic health records (EHRs). The study evaluated blood pressure control in 156 patients with uncontrolled hypertension enrolled in a home-based digitalmedicine blood pressure program and compared them with 400 patients in a usual-care group for 90 days. The patients submitted at least one blood pressure reading per week. 
AN ANALYSIS OF PGHD IN ASSISTING NURSES AND PHYSICIANS TO BETTER TREAT PATIENTS WITH HYPERTENSION

Digital-medicine patients completed questionnaires online were asked to submit at least one blood pressure reading/week and received medication management and lifestyle recommendations via a clinical pharmacist and a health coach. In addition, patients received monthly progress reports together with tips on healthy lifestyles based on their screening phenotype. Patients were also contacted by pharmacists and discussed the screening results and also treatment options for improving their blood pressure control. They were also encouraged to incorporated healthy lifestyles and medication options. Lastly, patients were directed to educational hypertension websites for further information.

Out of the 156 patients who enrolled in the digital-machine program for 90 days; $71 \%$ achieved blood pressure control compared to $31 \%$ of the usual-care group. Results indicated that a digital hypertension program was better because it showed significant improvement in blood pressure and lifestyle change. The journal by Rodriguez et.al (2019) explored how wirelessly transmitting home-based self-monitoring of blood pressure data (SMBP) measurements to an interactive web-based system that is linked to clinicians' EHR system. As interoperability remains a challenge with PGHD, this review gives some information of how providers are trying to integrate PGHD with EHRs.

Rodriguez et.al. (2019) studied thirteen primary care physicians. The physicians specialized in internal medicine and the primary care experience of providers ranged from 5 to 35 years. In addition, they were all utilizing SMBP in the management and diagnosis of hypertensive patients or suspected hypertensive patients (Rodriguez et al., 2019). The number of patients the providers saw each month ranged from 49 to 256 
AN ANALYSIS OF PGHD IN ASSISTING NURSES AND PHYSICIANS TO BETTER TREAT

PATIENTS WITH HYPERTENSION

patients. A total of 5 interviews were conducted and questions were open-ended and questions centered on (1) the value of SMBP in hypertension care, (2) needs of viewing SMBP and desired visual display, (3) desired alert algorithm and critical values, (4) needs for other PHGD, (5) workflow of primary care team in utilizing SMBP.

Results showed that SMBP that were wirelessly connected to EHR systems yielded more objective data comparing to the values reported by patients. Most of the primary care providers considered home SMBP as an important tool in hypertension management (Rodriguez et al. 2019). The majority of providers preferred all SMBP measurements to be displayed in the EHR in a table format for easy reading.

Milani et al. (2016) study had limitations because it focused on a single-center and the participants were required to possess a smartphone to enroll in the research. Concerns about these limitations include education, socioeconomic, and motivational biases but their population was not biased towards those that are tech-savvy since the mean population was 68-years-old. Again, Rodriguez et al. (2019) study also had limitations because they focused on primary physicians from one academic medical center. It would have been better if they had physicians from different areas and/or environment. 
AN ANALYSIS OF PGHD IN ASSISTING NURSES AND PHYSICIANS TO BETTER TREAT

PATIENTS WITH HYPERTENSION

Figure 1

\section{Flow Chart of the Results from PGHD Literature Search}
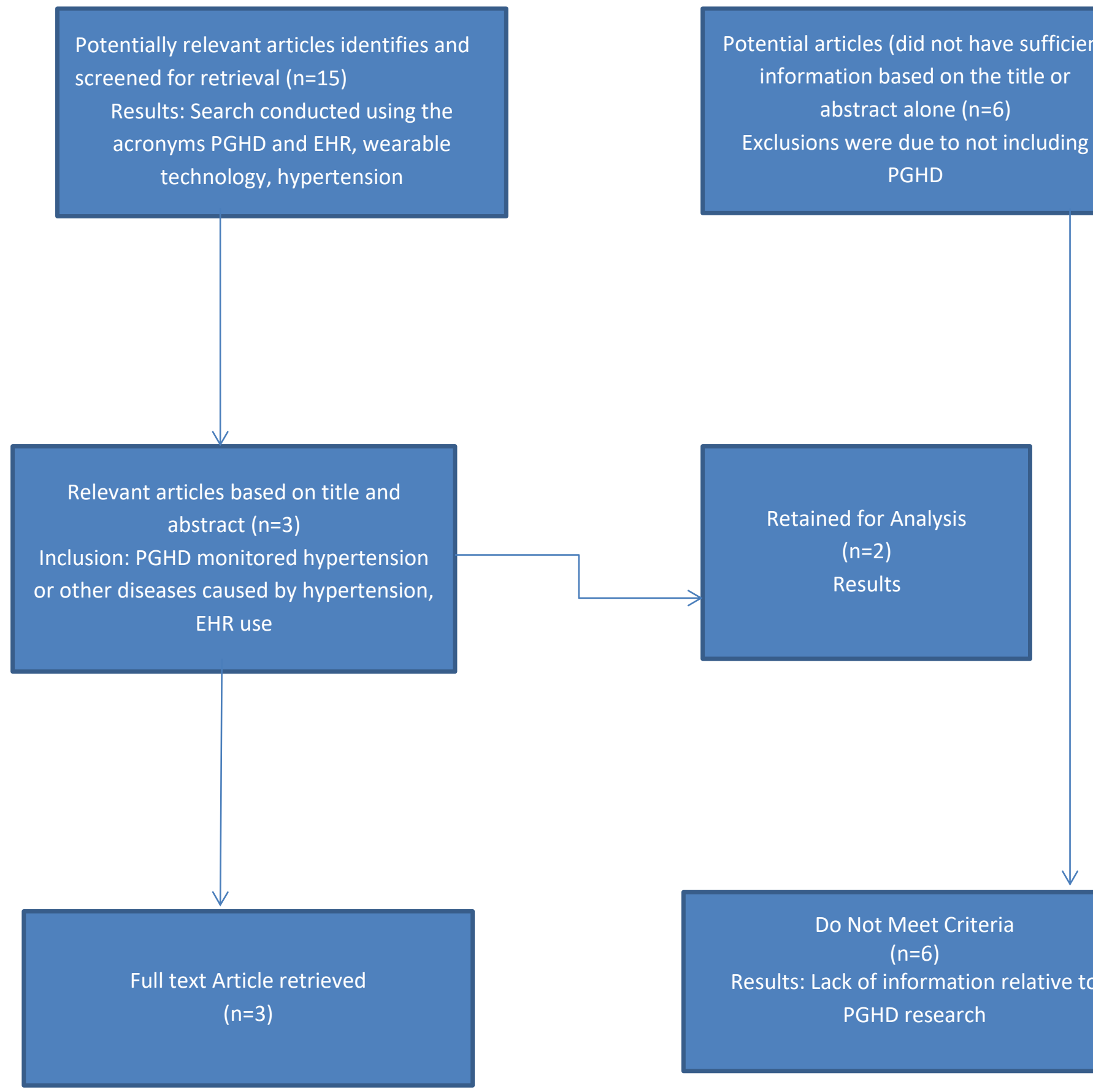

\section{PGHD}

Retained for Analysis

$$
(n=2)
$$

Results
Do Not Meet Criteria $(n=6)$

Results: Lack of information relative to

PGHD research 
AN ANALYSIS OF PGHD IN ASSISTING NURSES AND PHYSICIANS TO BETTER TREAT

PATIENTS WITH HYPERTENSION

Both studies conclude that patients who use PGHD, and treatment or lifestyle options by clinicians were able to control their blood pressure. Results showed patients had increased awareness about their own health and this helped them feel more empowered. It is imperative for organizations to integrate PGHD with EHR systems as it allows physicians to operate more efficiently because they can give more time to patients that require office visits. Both studies needed to improve on the population criteria by widening the areas in which research was conducted. 
AN ANALYSIS OF PGHD IN ASSISTING NURSES AND PHYSICIANS TO BETTER TREAT

PATIENTS WITH HYPERTENSION

\section{Chapter 3 - Methodology}

\section{Research Design}

This project is designed to gain an understanding of how PGHD is helping nurses and physicians to better treat patients with hypertension. The survey has three demographic in nature questions (age range and gender), two open-ended questions and three answers based on a psychometric response scale.

\section{Population and Sample Design}

The study will be limited to nurses and physicians treating patients with hypertension. The patients must be using PGHD and submitting data to the healthcare providers. The patients this project are adults with hypertension with age ranging from eighteen to seventy (18 years -70 years). The decision was to send 100 surveys through email with the hopes of receiving more responses.

\section{Data Collection Procedures}

Survey links were sent out using emails to all participants. The survey was composed mostly of closed-ended statements followed by a Likert scale. The last two questions were open-ended questions to give the participants the ability to share their perceptions in detail. The surveys were distributed over a period of three months to allow more responses due to the COVID-19 pandemic. 
AN ANALYSIS OF PGHD IN ASSISTING NURSES AND PHYSICIANS TO BETTER TREAT

PATIENTS WITH HYPERTENSION

Figure 2 - Survey Cover Letter

Patient -Generated Health Data (PGHD) Survey for physicians/nurses when

$\underline{\text { treating patients with hypertension }}$

Dear Participant,

I hope this finds you well. My name is Diana Sevenzayi and I am a graduate student for Health Information Management with the UTHSC. I am nearing the end of my program and I am required to do research. My topic is - An analysis of Patient-Generated Health Data (PGHD) on how it is assisting nurses and physicians to better treat patients with hypertension. I am reaching out to you to ask if you and your staff would be willing to take a survey on how PGHD is assisting you to better treat your patients. I understand these are very busy times for you. I would greatly appreciate your input.

Regards,

Diana 
AN ANALYSIS OF PGHD IN ASSISTING NURSES AND PHYSICIANS TO BETTER TREAT

PATIENTS WITH HYPERTENSION

Figure 3 - Survey

Patient-Generated Health Data (PGHD) Survey for physicians/nurses when treating patients with hypertension

1. How often do patients submit PGHD per week?

$0-2 \square$

2. Which age range submits the most data? $18-29 \square$

3. Which age range submits the least data? $18-29 \square$

4. How often do you encourage patients to use PGHD? always $\square$

5. Gender with the most PGHD submissions.

$40-49 \square$

$50-59 \square$

$60-70 \square$

sometimes $\square$

never $\square$

6. How strongly do you agree with the following statements?

\begin{tabular}{|l|l|l|l|l|l|l|}
\hline & Agree & $\begin{array}{l}\text { Strongly } \\
\text { Agree }\end{array}$ & $\begin{array}{l}\text { Somewhat } \\
\text { Agree }\end{array}$ & Disagree & $\begin{array}{l}\text { Somewhat } \\
\text { Disagree }\end{array}$ & $\begin{array}{l}\text { Strongly } \\
\text { Disagree }\end{array}$ \\
\hline PGHD improves patients' treatments & & & & & \\
\hline $\begin{array}{l}\text { PGHD helps providers and nurses to } \\
\text { better treat patients }\end{array}$ & & & & & \\
\hline $\begin{array}{l}\text { Patients understand the data they } \\
\text { collect on their wearables }\end{array}$ & & & & & & \\
\hline
\end{tabular}

7. How has PGHD helped you as a physician/nurse to treat patients?

8. What challenges have you faced with PGHD as a physician/nurse? 
AN ANALYSIS OF PGHD IN ASSISTING NURSES AND PHYSICIANS TO BETTER TREAT

PATIENTS WITH HYPERTENSION

\section{Data Analysis}

The ages and gender of patients using PGHD Data analysis will be performed using Qualtrics survey software. Data will be collected for each question and calculated. After 100 surveys were emailed, 21 responded which gave a $21 \%$ response rate. The first question showed us how many times patients were submitting their data. The age range and gender questions allow us to see how age and gender differences were utilizing PGHD in order to better manage hypertension.

\section{Response Rate}

The number of participants is estimated to be between 50-100. 
AN ANALYSIS OF PGHD IN ASSISTING NURSES AND PHYSICIANS TO BETTER TREAT

PATIENTS WITH HYPERTENSION

\section{Chapter 4 - Results}

The data from the survey questionnaire were analyzed and percentages displayed the results for each response from each participant. The answers were scored with the most positive "Strongly Agree" and the most negative "Strongly Disagree". There were two answers for age group: 18-29, 30-39, 50-59, and 60-70 years. Participants chose the answers with the most and least ranges. One answer was to provide the gender that submitted the most PGHD.

Results showed that on average patients submit PGHD twice per week with females submitting the most data. The age range with the most data submissions was 3039(40\%), 60-70(40\%), and 40-49(20\%). This shows how patients $60-70$ are more active in their health participation and also how they have embraced technology to help with help hypertension management. All nurses and physician agree that they always encourage patient to use PGHD. In addition, nurses and physicians agreed that PGHD helps them to better treat their patients because they can customize care and treatment, improves patient and physician communication, promotes activity levels, etc. However, there are challenges such as compliance issues with devices /wearables used by patients, sometimes devices alarms patients with false data e.g. elevated heart rates which can cause panic and stress to patients. 
AN ANALYSIS OF PGHD IN ASSISTING NURSES AND PHYSICIANS TO BETTER TREAT PATIENTS WITH HYPERTENSION

Graph 1 - PGHD submissions per week

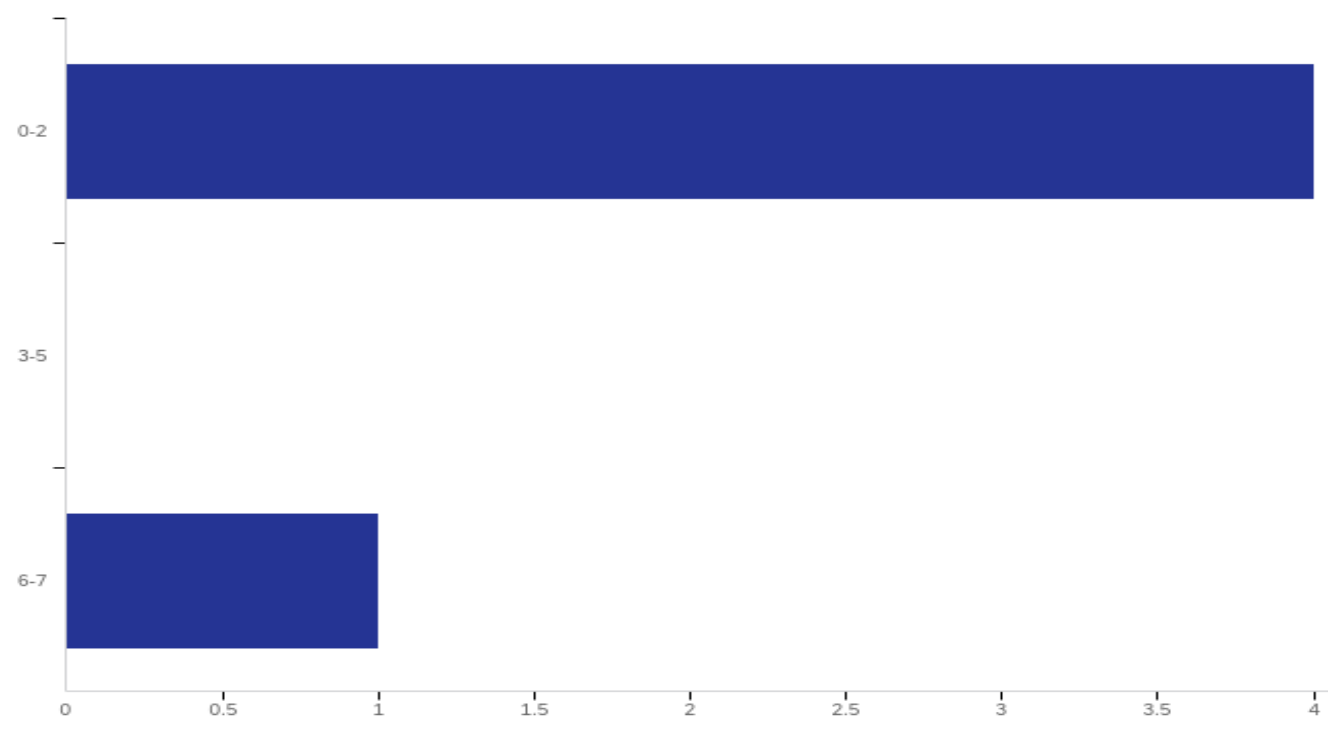

Graph 2 - Age range with the most data

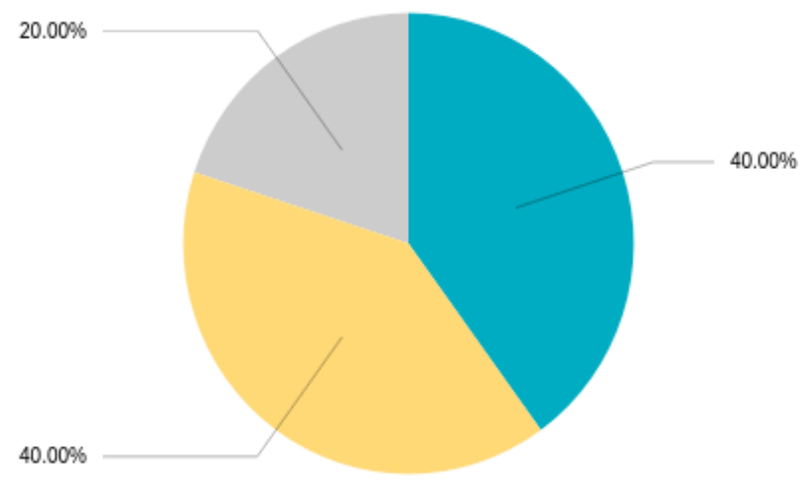

30-39 $\quad 60-70 \quad$ All Others 
AN ANALYSIS OF PGHD IN ASSISTING NURSES AND PHYSICIANS TO BETTER TREAT PATIENTS WITH HYPERTENSION

Graph 3 - How often do nurses/physicians encourage PGHD?

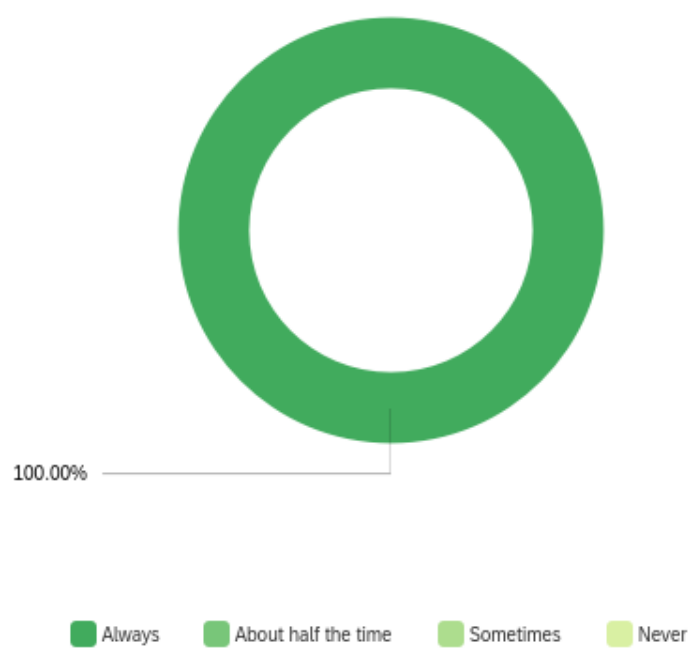

Graph 4 - Gender with the most PGHD submissions

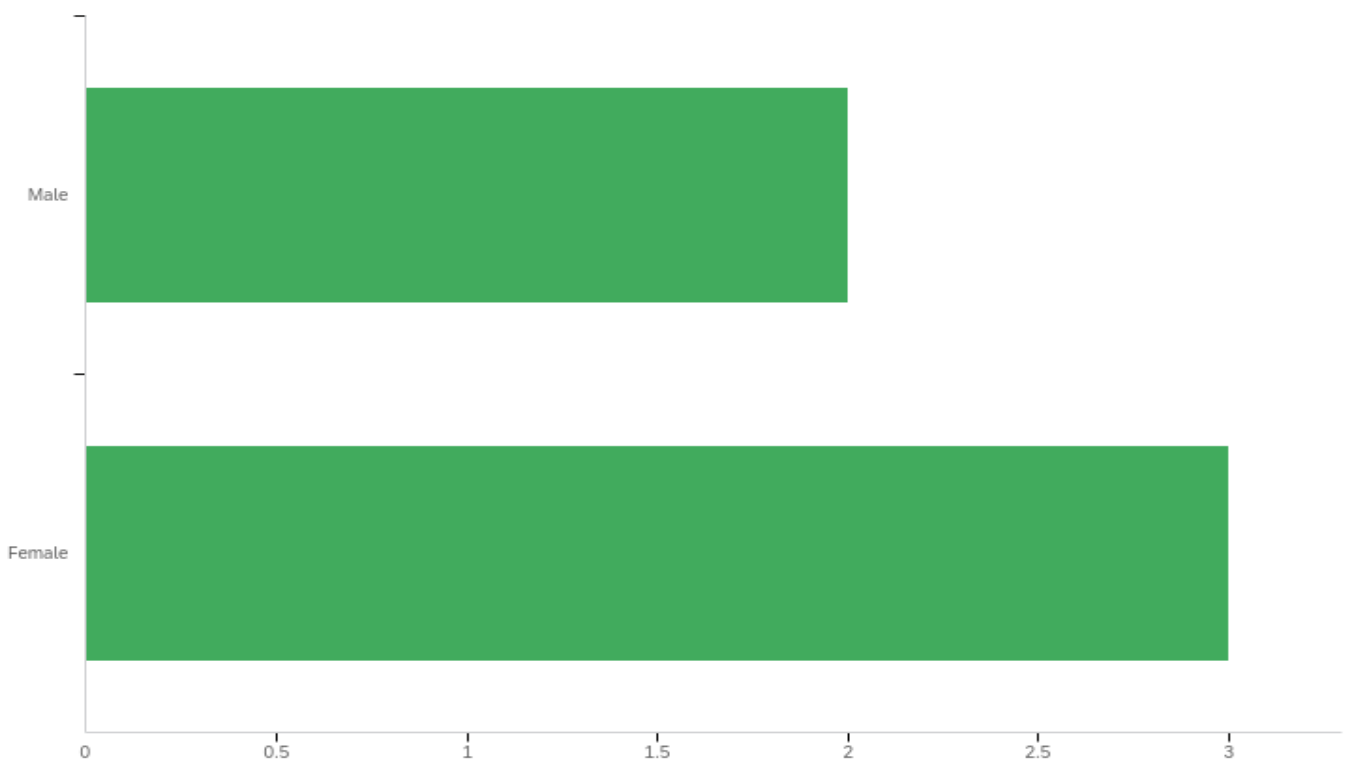


AN ANALYSIS OF PGHD IN ASSISTING NURSES AND PHYSICIANS TO BETTER TREAT PATIENTS WITH HYPERTENSION

Graph 5 - PGHD helps providers/nurses to better treat patients

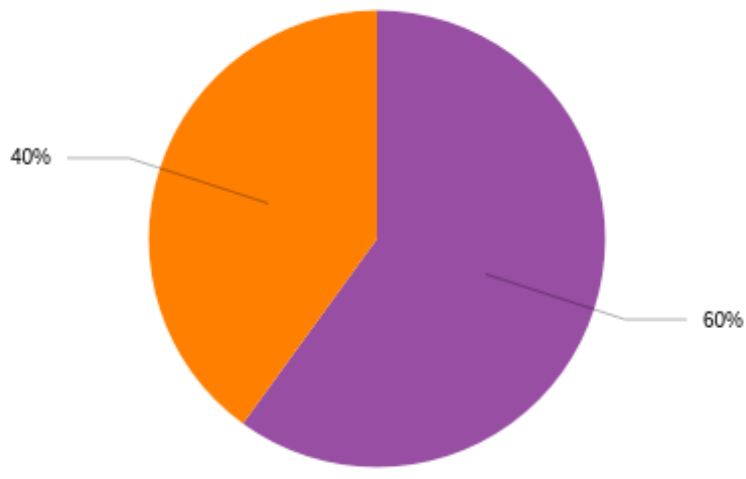

Agree Strongly Agree Somewhat Agree Disagree Strongly Disagree

Graph 6 - Patients understand the data they collect.

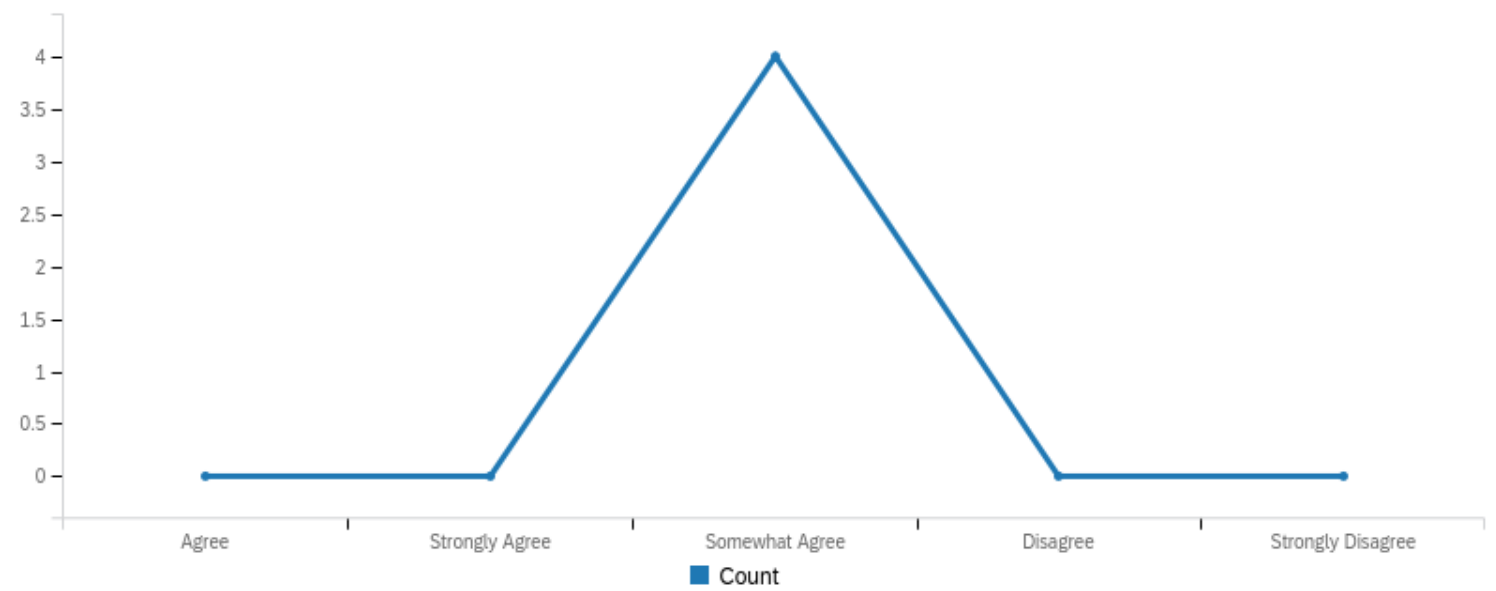




\section{How has PGHD helped you as a physician/nurse to treat patients?}

Helps to customize care and treatment

Helps to promote increased activity levels

Patients are autonomous in their care and for gathering information, which helps solidify a patient to physician/nurse relationship / rapport. It establishes teamwork and can provide more frequent information / trends of a patient in a more expeditious manner.

it saves time and ensure accuracy of the patients information

Allows me to more quickly titrate and adjust medications.

\section{What challenges have you faced with PGHD as a physician/nurse?}

Patient compliance

Sometimes it alarms people with false data (elevated heart rates)

Patients who are not tech-savvy or familiar with wearables and electronic devices and how to use it. Or may not want to learn and/or use this type of service and/or device.

illiteracy and some patient not cooperative

Sometimes the data submitted by patient can be difficult to interpret.

\section{Summary of Findings}

All participants the responded to the survey questionnaire were nurses or physicians treating patients with hypertension. Results showed that nurses and 
AN ANALYSIS OF PGHD IN ASSISTING NURSES AND PHYSICIANS TO BETTER TREAT PATIENTS WITH HYPERTENSION

physicians agree that PGHD helps them to treat patients to better manage hypertension. All participants agreed that PGHD helps improve communication between patients and health care providers. In addition, they are able to quickly adjust medications if patients are not responding well or reacting to certain medications. Some challenges that were highlighted in the responses include, health illiteracy whereby patients do not understand the meaning of the numbers they send to providers, some patients' not cooperating when given advice or sending data, and some data provided maybe difficult to interpret, etc. Overall, all participants agree that PGHD is important when treating patients with hypertension.

Although there are concerns about patient literacy, accuracy and security of devices; physicians and nurses agree that patient health improves significantly when using PGHD because providers can monitor the effectiveness of treatments and lifestyle behaviors of patients. Also, providers are able to guide patients and intervene quicker as compared to when they physically visit their healthcare provider's office. Lastly, patients become more involved in their health. 
AN ANALYSIS OF PGHD IN ASSISTING NURSES AND PHYSICIANS TO BETTER TREAT

PATIENTS WITH HYPERTENSION

\section{Chapter 5 - Conclusions and Recommendations}

\section{Summary of Findings}

From the responses received, the overall and individual answers to the Likert scale questions about PGHD use were positive. Advantages and challenges regarding PGHD were provided by nurses and physicians but the responses show that advantages outweigh the challenges. The comparison gender use of PGHD showed that females submitted more data on a weekly basis compared to males. Also, the comparison between age groups submitting the most data showed that 30-39 and 60-70 years old submitted the most data. This was interesting to because the 18-29 age range would be expected to submit the most data because they are technically savvy but results showed the opposite. It may also be that the range does not have many individuals suffering from hypertension and using PGHD. Sixty percent of responses showed that PGHD helps nurses and physicians to better treat patients with hypertension. Lastly, most responses showed that most patients do not understand the data they are collecting due to health illiteracy.

\section{Conclusions}

Nurses and physicians agree that PGHD helps when treating patient s with hypertension. Some responses highlighted that there were challenges with PGHD such as patients not being cooperative, unable to use the wearables and health illiteracy. However, most nurses and physicians agreed that PGHD helps to better treat patients with hypertension and they encourage patients to use PGHD to improve their condition. 
AN ANALYSIS OF PGHD IN ASSISTING NURSES AND PHYSICIANS TO BETTER TREAT

PATIENTS WITH HYPERTENSION

Patients become more engaged in their health and communication between healthcare providers and patient is improved when using PGHD.

\section{Recommendations}

This research study provides a glimpse into how PGHD is assisting nurses and physicians to better treat patients with hypertension. A more detailed study needs to be done with a larger sample to gather more data to further understand the topic. Results showed that patients need to be educated about PGHD in order to understand the meaning of the data they are collecting. 
AN ANALYSIS OF PGHD IN ASSISTING NURSES AND PHYSICIANS TO BETTER TREAT

PATIENTS WITH HYPERTENSION

\section{References}

Merai R, Siegel C, Rakotz M, Basch P, Wright J, Wong B., Thorpe P. CDC Grand Rounds: A Public Health Approach to Detect and Control Hypertension. (2016) Morbidity and Mortality Weekly Report. 18; 65(45):1261-1264.

Milani, R. V., Lavie, C. J., Bober, R. M., Milani, A. R., Ventura, H. O. (2017). Improving hypertension control and patient engagement using digital tools. The American Journal of Medicine. 130, 14-20.

Mozaffarian, D. et al. (2015). American Heart Association Statistics Committee and Stroke Statistics Subcommittee Heart disease and stroke statistics. The American Heart Association: 10.1161/CIR.0000000000000152.

Nwankwo, T., Yoon, S., Burt, V., Gu, Q. Hypertension among adults in the United States: national health and nutrition examination survey (2011-2012). National Center for Health Statistics Data Brief. (133)1-8.

Ostchega, Y., Yoon, S., Hughes, J., Louis T. (2006) Hypertension awareness, treatment, and control-continued disparities in adults: United States. National Center for Health Statistics Data Brief. (3) 1-8.

Plastiras, P. and O'Sullivan, D. (2018). Exchanging personal health data with electronic health records: A standardized information model for patient generated health data and observations of daily living. International Journal of Medical Informatics.120:116-125 doi: 10.1016/j.ijmedinf.2018.10.006. 
AN ANALYSIS OF PGHD IN ASSISTING NURSES AND PHYSICIANS TO BETTER TREAT

PATIENTS WITH HYPERTENSION

Rodruguez, S., Hwang, K., Wang, J., (2019). Connecting home-based self-monitoring blood pressure data into Electronic Health Records for hypertension care: A qualitative inquiry with primary care providers. Journal of Medical Internet Research.3 (2):e10388 doi: 10.2196/10388

Shapiro, M., Johnston, D., Wald, J., Mon, D. (2012). Patient-Generated Health Data. White Paper. Retrieved from https://www.healthit.gov/sites/default/files/rti_pghd_whitepaper_april_2012.pdf

Yoon S.S., Fryar CD, Carroll(2015). Hypertension Prevalence and Control among adults: United States, 2011-2014. National Center for Health Statistics. 
AN ANALYSIS OF PGHD IN ASSISTING NURSES AND PHYSICIANS TO BETTER TREAT

PATIENTS WITH HYPERTENSION

Appendix A - Consent Form

\section{CONSENT DISCLOSURE STATEMENT}

Title of Research: An analysis of PGHD in treating patients with hypertension

This is a research survey to address the question, How does PGHD assist physicians and nurses to better treat patients with hypertension? You are given an opportunity to participate in this survey.

I, Diana Sevenzayi, am a student at The University of Tennessee Health Science Center in the Health Informatics and Information Program and, I will be gathering information and analyzing the data received from this survey. This project is being completed under the supervision of Sajeesh Kumar, PhD, who can be contacted at skumar10@uthsc.edu or (901) 448-2125.

This survey consists of 8 questions. It is anticipated that this survey will take approximately 15 minutes, and participation is voluntary. You have the right not to answer any questions and to stop the survey at any point. Identifiable data will not be used in reporting of results, and aggregate data will be used whenever possible. The following measures will be taken to ensure the confidentiality of all data received: no personal data will be collected.

You may contact Cameron Barclay, MSA, UTHSC IRB Director, at 901-448-4824, or visit the IRB website at http://www.uthsc.edu/research/compliance/irb/ if you have any questions about your rights as a research subject, or if you have questions, concerns, or complaints about the research.

Funding for this survey has not been received and incentives will not be paid to you. Follow-up contact with you concerning the survey will not be made.

Your participation is voluntary, and if you choose not to participate or stop participating at any time, your decision will not result in a penalty or affect your rights. Potential risks include tiring from answering questions and loss of confidentiality. There will be no direct benefits for you in this survey, but the knowledge gained will provide valuable information as to the benefit or not of patient-generated health data for patients with hypertension.

If there are questions pertaining to this survey, please contact Diana Sevenzayi at (971) 2852807 or dsevenza@uthsc.edu. 


\section{Appendix B - Survey Questionnaire}

\section{Patient-Generated Health Data (PGHD) Survey for physicians/nurses when treating patients with hypertension}

1. How often do patients submit PGHD per week? $0-2 \square \quad 3-5 \square$

2. Which age range submits the most data? 18-29 $\square \quad 30-39 \square \quad \square \quad 40-49 \square \quad 50-59 \square \quad 60-70 \square$

3. Which age range submits the least data? 18-29 $\square \quad 30-39 \square \quad \square \quad 40-49 \square \quad 50-59 \square \quad 60-70 \square$

4. How often do you encourage patients to use PGHD? always $\square \quad$ sometimes $\square \quad$ never $\square$

5. Gender with the most PGHD submissions. $\quad$ Male $\square \quad$ Female

6. How strongly do you agree with the following statements?

\begin{tabular}{|c|c|c|c|c|c|c|}
\hline & Agree & $\begin{array}{l}\text { Strongly } \\
\text { Agree }\end{array}$ & $\begin{array}{l}\text { Somewhat } \\
\text { Agree }\end{array}$ & Disagree & $\begin{array}{l}\text { Somewhat } \\
\text { Disagree }\end{array}$ & $\begin{array}{l}\text { Strongly } \\
\text { Disagree }\end{array}$ \\
\hline PGHD improves patients' treatments & & & & & & \\
\hline PGHD helps providers and nurses to better treat patients & & & & & & \\
\hline Patients understand the data they collect on their wearables & & & & & & \\
\hline
\end{tabular}

7. How has PGHD helped you as a physician/nurse to treat patients?

8. What challenges have you faced with PGHD as a physician/nurse? 